\title{
RECOMPRA DE AÇÕES: REGULAMENTAÇÃO E PROTEÇÃO DOS MINORITÁRIOS
}

RESUMO

O objetivo deste trabalho é rever a legislação brasileira referente ao processo de recompra de ações, inclusive as recentes mudanças com a introdução da Instrução CVM no 299, e analisar o seu impacto sobre os acionistas minoritários. Antes dessa Instrução, as recompras de ações poderiam sinalizar um fechamento branco de capital. N esse caso, os acionistas minoritários poderiam ser prejudicados. A pesquisa foi realizada a partir de uma amostra dos anúncios de recompra de ações realizados na BOVESPA no período entre janeiro de 1994 e junho de 2002, e confirmou-se que, em média, os acionistas minoritários tiveram um retorno acumulado de - 10\% durante os três meses após o anúncio da recompra das ações. Concluiu-se que, após a promulgação da Instrução CVM nำ299, as ações passaram a obter retornos anormais acumulados positivos, beneficiando os acionistas.

\section{Marcio Fernandes Gabrielli \\ ESPM e FGV-EAESP}

\section{Richard Saito}

FGV-EAESP

\begin{abstract}
This article reviews the legal aspects regarding the share repurchase process, including the recent changes introduced by the CVM Instruction \#299, and analyze its impact on minority shareholders. Prior to the introduction of CVM \#299, share repurchases could signal that the company would go private. This could expropriate the minority shareholders. We empirically test based on a sample with all share repurchase on BOVESPA from January 1994 to June 2002, and confirm that on average the minority shareholders had an accumulated return of - 10\% within three months after the announcement of share repurchase. After the enactment of the CVM Instruction \#299, there was evidence of positive cumulative abnormal returns for the announced share repurchase programs, bringing benefits to minority shareholders.
\end{abstract}

PALAVRAS-CHAVE Recompra de ações, Instrução CVM nำ299, proteção dos acionistas minoritários, regulamentação. KEY WORDS Share repurchase, Instruction CVM \#299, expropriation of minority shareholder, regulation. 


\section{INTRODUÇÃO}

A aquisição de ações de sua própria emissão, ou recompra de ações, realizada por uma companhia de capital aberto em bolsa de valores vem crescendo significativamente em vários mercados acionários do mundo nos últimos anos, transformando-se em um importante meio de distribuição de caixa para os acionistas em substituição ao pagamento de dividendos.

Entende-se por recompra de ações a mercado o mecanismo que se inicia quando uma empresa anuncia para o mercado sua intenção em adquirir uma determinada quantidade de ações de sua própria emissão junto ao mercado acionário. A partir de então, a empresa encontra-se apta a comprar, assim como qualquer outro investidor, as ações de sua própria emissão na Bolsa de Valores, até uma determinada quantidade máxima e durante um determinado prazo, estipulados por lei. As ações recompradas são mantidas durante um certo período de tempo na tesouraria da companhia até serem recolocadas novamente no mercado acionário.

Segundo Jagannathan et al. (2000), entre 1985 e 1996 o número de anúncios de recompra de ações feitos por companhias norte-americanas cresceu $650 \%$, de 115 para 755, e o valor desses anúncios cresceu $750 \%$, de US\$ 15,4 bilhões para US\$ 113 bilhões. Em contrapartida, o aumento no pagamento de dividendos apenas dobrou, de US $\$ 67,6$ bilhões para US $\$ 141,7$ bilhões, no mesmo período. Conseqüentemente, de acordo com Grullon e M ichaelly (2002), a razão entre o valor das recompras de ações e o valor total de dividendos distribuídos cresceu de 13,1\% em 1980 para $104,4 \%$ em 1998, sendo este o primeiro ano na história do mercado de capitais dos Estados U nidos em que as empresas gastaram mais na recompra de suas ações, da ordem de US\$181,8 bilhões, do que em pagamento de dividendos, no valor de US\$174,1 bilhões.

Dados de outros países também revel am um aumento do número de programas de recompra de ações. Segundo I kenberry et al . (2000), no mercado canadense foram observados 1.060 anúncios de recompra de ações entre 1989 (US\$ 5,136 bilhões) e 1997 (US\$ 9,660 bilhões), totalizando mais de US\$ 35 bilhões no período. No mercado europeu pôde ser observado um crescimento de $600 \%$ no número de anúncios de recompras entre 1990 e 1998, passando de 31 para 217 (Lasfer, 2002). Conforme Lamba e Ramsay (2000), na Austrália esse número elevou-se de cerca de 30 entre 1989 e 1995 para mais de 100 entre 1996 e 1999.
Além desse crescimento significativo, a recompra de ações tem recebido bastante atenção na literatura acadêmica devido ao lucro proporcionado aos acionistas. Dann (1981), Vermaelen (1981; 1984), Lakonishok e Vermaelen (1990), Comment e Jarrell (1991) e Iken berry et al. $(1995 ; 2000)$ documentaram retornos anormais positivos para o preço das ações em torno de um anúncio de recompra.

Entretanto, ao ser analisado o mercado brasileiro entre 1ํ de janeiro de 1994 e 30 de junho de 2002, encontrou-se um anormal retorno acumulado médio negativo de $-3,48 \%$, referente ao dia do anúncio do programa de recompra de ações até o término do prazo de três meses previsto para a recompra. A partir desse resultado, levantaram-se hipóteses para explicar o porquê dessa discrepância entre os resultados encontrados na literatura internacional e o mercado brasileiro.

Segundo Kim e Schremper (2002), o aumento de importância da recompra de ações nos últimos anos está intimamente ligado à legislação vigente nos países, ou melhor, à desregulamentação desses mercados no que se refere às leis que regem os mercados de capitais. A recompra de ações era vetada até recentemente em vários países, devido ao receio existente de uma possível manipulação dos preços das ações pela companhia emissora. Por exemplo, na Austrália a legislação proibia a recompra de ações até 1989, e até 1995 havia uma regulamentação muito restritiva; no Reino Unido os programas de recompra de ações foram legalizados em 1981, mas com fortes restrições em termos de quantidade, duração, preços e impostos, se comparados aos do mercado norte-americano; no Japão a recompra de ações era proibida até 1994; na Alemanha até 1998; na Suíça até 1992; e em Hong Kong até 1991. Além disso, existem mercados nos quais a recompra de ações ainda é proibida, ou ainda, caso da Áustria, onde é permitida apenas para fazer frente aos planos de remuneração de executivos com stock options.

Jagannathan et al. (2000), Grullon e Michaely (2002) e Kim e Schremper (2002), abordando o mercado norte-americano, argumentam que foi somente após a aprovação da regra 10b-18 da Securities Exchange Comission (SEC), em 1982, que as recompras de ações ganharam novo impulso no país. Antes dessa regra, a empresa que realizasse um programa de recompra de ações estava sob a ameaça de encargos decorrentes da Lei Antimanipulação de Preços de 1934 (Rule 10b-5 of the Securities Exchange Act of 1934). 
Tendo em vista a importância da legislação vigente nos diversos países sobre os mecanismos de recompra de ações, neste artigo se trabalha a hipótese de que a legislação brasileira possa explicar as razões da reação negativa do mercado nacional aos anúncios de recompras de ações. $N$ esse caso, apesar de a legislação permitir desde 1976 a aquisição de ações pela própria companhia emissora - sob determinadas condições - , a influência do fator legal se mostrou presente apenas na última década, período durante $o$ qual se obteve a amostra para a realização do presente estudo. A Instrução CVM no 268 alterou em 1997 a quantidade máxima de ações a serem recompradas. Porém, foi a Instrução CVM no 299, de 1999 - que dificultou 0 chamado "fechamento branco" de capital das companhias cujas ações eram transacionadas em bolsa de valores -, que teve a maior influência nos resultados analisados. Entende-se por "fechamento branco" de capital o que ocorre quando os acionistas majoritários de uma companhia vêm a deter um percentual que limite a liquidez das ações em circulação, prejudicando dessa forma os acionistas minoritários, pois ceteris paribus um ativo tem seu preço reduzido, com uma diminuição de sua liquidez. Esse aumento do percentual dos acionistas controladores poderia ser obtido por intermédio de sucessivos programas de recompra de ações, os quais retirariam do mercado ações em circulação, ou seja, detidas por acionistas minoritários.

Para atingir o objetivo de rever a legislação brasileira referente ao processo de recompra, este artigo está estruturado da seguinte forma. N a primeira parte são apresentados os métodos utilizados e a motivação das companhias na recompra de suas ações, assim como uma descrição do processo e um resumo da legislação vigente reguladora do processo no Brasil. Na segunda parte, descreve-se a metodologia de teste empregada na pesquisa empírica, cujos resultados são mostrados e analisados na terceira parte. 0 artigo é final izado com a apresentação das conclusões.

\section{FUNDAMENTOS CONCEITUAIS}

\section{Métodos de recompra de ações}

De acordo com Vermaelen (1981; 1984), Lakonishok e Vermaelen (1990), existem basicamente três métodos utilizados pelas empresas para recomprar suas ações. 0 primeiro é denominado oferta a preço fixo ( fixed-price tender offer), no qual a administração define 0 número de ações que pretende recomprar, as- sim como a data de expiração e o preço que pretende pagar - preço esse normalmente superior ao do mercado - , ficando a cargo do acionista vender ou não suas ações. No Brasil, esse método recebe o nome de Oferta Pública de Aquisição de Ações (OPA) e foi recentemente ajustado pela Instrução CVM no 361/02. Esse instrumento possui as seguintes modalidades: cancelamento de registro de companhia aberta, aquisição do controle, alienação de controle, aumento da participação do controlador, concorrente ou voluntária. Trata-se de uma oferta irrevogável e irretratável de compra ou permuta de ações e tem como destinatários todos os titulares de ações da mesma espécie e classe objeto da OPA. Entretanto, o estudo das OPAs foge do escopo deste trabal ho, o qual se concentra nas recompras de ações a mercado. Essa distinção é importante porque estudos estrangeiros já compararam formas similares desses processos existentes em outros mercados, como fizeram Vermaelen (1981) e Comment e Jarrel (1991). Isso se deve ao fato de ambos os mecanismos permitirem que as companhias envolvidas transacionem com suas ações, embora no Brasil os processos, motivações e regulamentação envolvidos sejam completamente distintos para ambos.

0 segundo método é conhecido como DutchAuction e foi estudado por Comment e Jarrel (1991) e Bagwell (1992). Presente no mercado norte-americano, não existe no Brasil. Segundo esse método, a administração define o número de ações que pretende recomprar, assim como a sua data de expiração e uma faixa com alguns preços que pretende pagar, normalmente com ágio sobre o preço de mercado. Dessa forma, os acionistas podem oferecer ou não as suas ações a qual quer um dos preços ofertados, sendo que a administração irá comprar a partir dos preços mais baixos até completar a quantidade previamente estipulada.

Nesses dois primeiros métodos normal mente há um ágio entre o preço de mercado e o preço ofertado, gerando conseqü entemente um retorno anormal instantâneo das ações. Vale ressaltar que, havendo acionistas interessados em vender suas ações pel o preço ofertado, a empresa é obrigada a recomprar a quantidade de ações anunciada.

0 terceiro método, tema deste artigo, é denominado recompra de ações a mercado. Consiste na aquisição de ações pela própria companhia emissora, em que as empresas simplesmente recompram as ações no mercado acionário como qualquer outro investidor, embora existam normalmente restrições legais, tanto na quantidade diária quanto no total de ações que a 
companhia pode recomprar. Agindo como qualquer outro investidor, a empresa paga exatamente o preço de mercado pelas ações recompradas e não é obrigada a recomprar toda a quantidade de ações anunciada, podendo inclusive chegar ao extremo de não recomprar uma única ação. No mercado americano, Stephens e Weisbach (1998) encontraram uma média entre 74 a $82 \%$ de ações efetivamente recompradas frente à quantidade anunciada para o período entre 1981 e 1990. Entretanto, esse estudo excluiu da amostra as recompras de ações anunciadas logo após a quebra da Bolsa de 1987. De acordo com Ikenberry et al. (1995), trata-se do método mais utilizado no mercado norteamericano, com $90 \%$ do valor financeiro dos anúncios de recompra de ações real izados entre 1985 e 1993.

De acordo com Comment e Jarrel (1991), devido ao ágio existente e à obrigatoriedade de aquisição das ações caso haja vendedores interessados, o poder de sinalização de uma oferta a preço fixo é muito maior que o de uma recompra a mercado. Segundo Vermaelen (1981), uma oferta a preço fixo apresenta um retorno anormal de $17,5 \%$ frente a $3,37 \%$ de uma recompra a mercado entre os dias imediatamente anteriores e posteriores ao anúncio.

Existem ainda alguns outros métodos de menor importância, tais como as transações privadas, nas quais as empresas podem eleger certos acionistas dos quais irão recomprar as ações, proibidas no Brasil, e a combinação de opções de compra e venda de ações.

\section{Motivações de um programa de recompra de ações}

Há quatro motivos principais pelos quais as empresas recompram suas próprias ações. 0 primeiro motivo é para ajustar sua estrutura de capital. Se uma empresa acha que está pouco endividada e que possui mais capital próprio do que necessita, uma recompra de ações pode restaurar um balanço mais adequado entre capital próprio e de terceiros. De acordo com G rinblatt e Titman (2002) , o ajuste da estrutura de capital via recompra de ações é bastante óbvio, pois ao retirar do mercado uma parcela de suas ações a empresa diminui a partici pação do capital próprio na sua estrutura de financiamento, aumentando, portanto, sua alavancagem.

O segundo motivo é para a redução dos custos de agência ou excesso de fluxos de caixa, isto é, o excesso de caixa que não encontra oportunidades para ser reinvestido lucrativamente no negócio e do qual se fará um uso inadequado se for deixado na companhia. Conforme Jensen e M eckling (1976), esse fato ten de a mitigar os conflitos de agência entre administradores e acionistas de uma mesma empresa. Estimativas de Li e McN ally (1999) para o mercado canadense dão suporte à hipótese da redução dos conflitos de agência.

0 terceiro principal motivo é a utilização do mecanismo de recompra de ações como um substituto mais flexível e com vantagens fiscais sobre o pagamento de dividendos, existente na maioria dos mercados mundiais, mas inexistente no mercado brasileiro, no qual existe uma desvantagem fiscal. A hipótese da substituição de dividendos por recompra de ações como uma forma al ternativa de transferência de caixa para os acionistas foi estudada por Grull on e Michaely (2002), que constataram que os investidores vêem recompras de ações e pagamento de dividendos como substitutos.

Segundo Stephens e Weisbach (1998), tanto os fluxos de caixa esperados quanto os não esperados são positivamente correlacionados com recompras de ações, sugerindo que as empresas ajustam ativamente suas recompras de ações à sua situação de caixa, explorando assim a maior flexibilidade proporcionada pelas recompras de ações e indicando uma das possíveis razões de sua crescente popularidade. Guay e Harford (2000) argumentam que os administradores irão preferir uma recompra de ações no caso de choques transitórios de aumento do fluxo de caixa, enquanto um aumento do pagamento de dividendos seria preferível no caso de um choque que tenha uma grande componente permanente. I sso se deve ao fato de o mercado não esperar novas recompras em prazos preestabelecidos.

0 impacto dos impostos pessoais sobre a decisão dos administradores quanto ao método de transferência de caixa a utilizar - se recompra de ações ou pagamento de dividendos - no mercado norte-americano foi estudado por Lie e Lie (1999). Suas análises encontraram resultados consistentes com a teoria de que diferentes taxações podem influenciar a decisão dos administradores, que penderia para as recompras de ações pelo fato de os ganhos de capital serem menos taxados que a distribuição de dividendos.

Entretanto, no caso brasileiro esse cenário não se mantém. La Porta et al. (2000) compararam as vantagens e desvantagens fiscais da distribuição de dividendos em relação ao ganho de capital em 33 países ao redor do mundo. Refazendo-se as contas para o caso do Brasil - que não foi incluído na pesquisa pelo fato de aqui existir a obrigatoriedade do pagamento de dividendos -, encontra-se uma vantagem fiscal para di videndos maior que em qual quer outro país da amostra. Como no Brasil existe a possibilidade do pagamen- 
to de juros sobre capital próprio, precisou-se calcular esta vantagem para três casos distintos. Analisando os dados calculados para o mercado brasileiro, a vantagem fiscal pende para o recebimento de dividendos, em vez dos ganhos de capital resultantes da recompra de ações. Dessa forma, ao contrário do que acontece na maioria dos países do mundo, em que é apontada como uma das hipóteses para a utilização do mecanismo de recompra de ações em substituição ao pagamento de dividendos, a vantagem fiscal não se aplica ao atual mercado brasileiro.

0 quarto e último motivo principal apontado como motivador para os programas de recompra de ações consiste na sinalização de uma companhia para o mercado cujo preço de suas ações se encontre subavaliado pelo próprio mercado. Por essa razão ocorrem diversos anúncios de recompra de ações após grandes quedas dos mercados de ações. Após o crash de 1987, quando o mercado norte-americano caiu mais de $20 \%$, cerca de 750 empresas anunciaram programas de recompra de ações nos dias seguintes à queda do mercado. Da mesma forma, nas duas semanas seguintes aos atentados terroristas de 11 de setembro de 2001, foram anunciados mais de 300 programas de recompras de ações. Essa mesma característica pode ser observada no mercado brasileiro, que registrou um pico de anúncio de recompra no biênio 1997 e 1998, e foi identificada por Procianoy e Moreira (2000) como sendo resultante da crise asiática e conseqüente grande queda nos preços das ações.

Dann (1981), Vermael en (1981), Comment e Jarrell (1991), Ikenberry et al. (1995; 2000) e Stephens e Weisbach (1998) sugerem uma correlação negativa entre 0 anúncio de um programa de recompra de ações e a performance da ação da empresa no período anterior ao anúncio. Isso dá suporte à hipótese de que os administradores decidem recomprar as ações de suas empresas quando julgam que elas se encontram subavaliadas, indicando um mercado imperfeito do ponto de vista informacional. Curiosamente, grande parte das empresas norte-americanas que anunciaram programas de recompra de ações após a quebra de 1987 nunca recompraram tais ações, pois a sinalização para o mercado funcionou tão bem que tais empresas nunca precisaram recomprar as ações. Isso pode corroborar a hipótese da sinalização, pela qual os administradores estariam sinalizando para o mercado que julgam que as ações de suas empresas se encontram subavaliadas e pretendem tirar vantagem disso por meio de uma recompra delas a um preço mais baixo.
A partir dessa discussão sobre sinalização, a primeira hipótese a ser testada é a seguinte:

H1: $O$ anúncio de um programa de recompra de ações terá um efeito positivo no preço das ações da empresa imediatamente após ser feito, e esse acréscimo no preço das ações manter-se-á acima do preço anterior até 0 final do período de recompra.

Dann (1981), em seu estudo a respeito da influência das recompras de ações sobre todas as fontes financiadoras, constatou que, embora os acionistas sejam os grandes beneficiários do anúncio de um programa de recompra de ações, nenhuma classe de valores mobiliários da empresa perde val or com o anúncio. Isso significa que não existe transferência de renda entre os diversos agentes financiadores, mas que há um aumento do valor da empresa como um todo, mostrando a relevância do fato.

Para finalizar essa discussão, é importante ressaltar que o mercado brasileiro de capitais é bastante concentrado e tem baixa liquidez para a maioria das ações transacionadas na BOVESPA. Dessa forma, há um ambiente desfavorável ao mecanismo de transferência de caixa, via recompra de ações, pois, para que haja uma efetiva transferência de caixa da empresa para os acionistas, as ações recompradas pela companhia devem ser necessariamente canceladas. Esse fato pode vir a influenciar negativamente a liquidez dessa ação, ao haver uma redução na quantidade de ações em circulação (free-float). Dessa forma, ao mesmo tempo em que existem forças agindo no sentido de uma melhora do preço das ações, há uma força agindo no sentido da diminuição do preço das ações, uma vez que quanto menor a liquidez de um ativo, maior o seu risco, menor a sua atratividade e menor, portanto, o seu preço. Saito (2003) encontrou um prêmio negativo pelo voto para ações ordinárias brasileiras em relação às preferenciais, devido principal mente à maior liquidez das ações preferenciais.

Entretanto, não há no mundo acadêmico um consenso a respeito da maneira como um processo de recompra de ações afeta a liquidez. Alguns autores, como Barclay e Smith (1988) e Brockman e Chung (2001), encontraram uma correlação entre recompra de ações e diminuição da sua liquidez, corroborando a explicação acima. Diferentemente, Franz et al. (1995) e Cook et al. (1996) obtiveram evidências de que a liquidez aumenta com a recompra de ações, ao passo que Miller e McConnell (1995) afirmam que as mudanças de 
liquidez são insignificantes. No entanto, devido às características particulares do mercado brasileiro, acredita-se que ele deva se comportar de maneira semeIhante à descrita no parágrafo anterior, com uma diminuição da liquidez.

\section{0 processo de recompra de ações no Brasil}

Pode-se sistematizar a mecânica de um programa de aquisição de ações de sua própria emissão por uma companhia da seguinte maneira. Primeiramente, a companhia informa à BOVESPA sua intenção de realizar um programa de recompra de ações. Segue-se uma Reunião do Conselho de Administração (RCA) e a decisão sobre a realização de um programa de recompra de ações, com a definição das seguintes características: data de início do programa; prazo no qual a companhia poderá recomprar suas ações (máximo de três meses); classes e quantidades de ações a serem recompradas (máximo de $10 \%$ das ações em circulação de cada classe); destino das ações a serem recompradas; e sociedades financeiras intermediárias do processo. Segue-se à RCA a divulgação para o mercado por meio de um "fato relevante".

Com isso, tem-se o início do programa de recompra de ações, no qual há a aquisição factível, não obrigatória, pela companhia de ações de sua própria emissão na bolsa de valores, pelo preço de mercado e sem redução do capital social. Após o término do prazo estipulado, durante o qual a companhia poderia recomprar suas ações, poderá haver uma nova RCA que poderá deliberar, dentre outras coisas, pela prorrogação do prazo para recompra das ações (mais três meses), por um novo programa de recompra de ações, subseqüente ao primeiro, e sobre o destino das ações efetivamente recompradas.

Uma linha de tempo ilustrativa de uma típica recompra de ações no mercado brasileiro, com prazo de recompra prorrogado, pode ser vista na Figura $1 . \mathrm{Na}$ pesquisa realizada, os prazos mais comuns encontrados são os identificados, o que não significa que isso seja válido de forma geral.

\section{Legislação brasileira}

A base legal sobre a qual está disposta a possibilidade de uma companhia adquirir ações de sua própria emissão encontra-se na Lei ํo 6.385 , de 7 de dezembro de 1976 - que regulamenta o mercado de valores mobiliários e cria a CVM -, e na Lei no 6.404, de 15 de dezembro de 1976 - Lei das Sociedades Anônimas. Esta última lei estende a todas as companhias a faculdade de adquirir ações de sua própria emissão, até então restrita às companhias com capital autorizado por disposição da Lei no 4.728/65. O tratamento dado pela Lei das Sociedades Anônimas à hipótese de negociação pelas companhias com ações de sua própria emissão abrandou o princípio de restrição genérico, permitindo em caráter de exceção, entre outras operações, a aquisição para cancelamento ou manutenção em tesouraria, bem como a posterior alienação desses títulos.

Várias instruções foram baixadas posteriormente para melhor regular o mecanismo de recompra de ações, sendo a Instrução CVM no 10, de 14 de fevereiro de 1980 , a primeira e mais extensa a respeito do tema. Negócios que infrinjam as normas diretamente ligadas às operações de aquisição das próprias ações estarão sujeitos à pena de nulidade. 0 percentual má-

Figura 1 - Ilustração de uma típica recompra de ações no mercado brasileiro, com prorrogação de prazo.

Fato relevante: divulgação $\mathrm{p} /$ mercado
Fato relevante: prorrogação

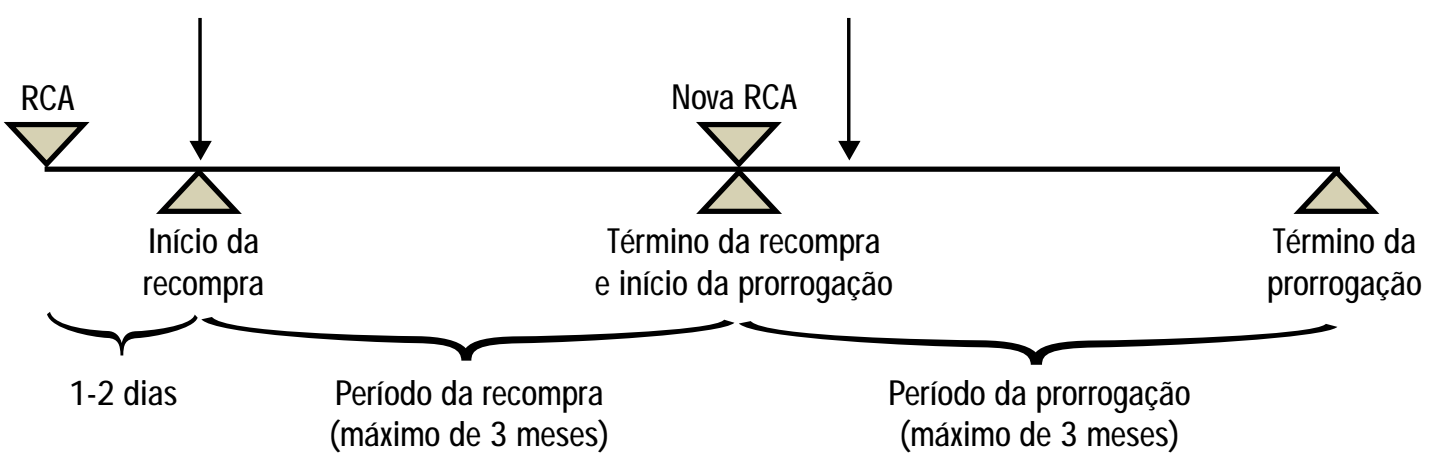

OUT./DEZ. $2004 \cdot$ - ORAE • 59 
ximo de ações que podem ser recompradas do mercado variou significativamente desde a sua fixação em $5 \%$ de cada classe de ação pela Instrução CVM № 10. Entretanto, esse limite diz respeito ao número de ações em circulação - e não no total de ações emitidas pela companhia - e às ações que podem ser mantidas em tesouraria, não podendo ser ultrapassado por meio de autorizações consecutivas de recompra de ações. A Instrução CVM no 100, de 13 de junho de 1989, elevou esse limite para $10 \%$, e ele foi novamente reduzido após alguns meses aos mesmos $5 \%$ iniciais, pela Instrução CVM no 111, de janeiro de 1990. O limite aumentou outra vez para $10 \%$ por intermédio da Instrução CVM no 268, de 13 de novembro de 1997, e se manteve inalterado até a data da real ização deste trabalho.

A instrução CVM no 229, de 16 de janeiro de 1995, dispôs sobre o cancelamento de registro, regulamentando 0 artigo 21 da Lei no 6.385, de 7 de dezembro de 1976. Essa instrução regulamentou todas as etapas necessárias para uma companhia cancelar seu registro de companhia aberta. No entanto, não dispôs sobre medidas que pudessem dificultar o chamando "fechamento branco" de capital.

A Instrução CVM no 299, de 9 de fevereiro de 1999, deliberou sobre assuntos ligados à alienação de controle acionário, negociação com as próprias ações e ofertas públicas para a aquisição de ações, dificultando o "fechamento branco" de capital. Houve a inclusão de uma OPA obrigatória, quando o adquirente for acionista controlador, ou proeminente comprador, cuja participação acionária na época do negócio tenha se elevado efetiva ou potencialmente em $10 \%$ das ações da mesma espécie e/ou classe daquelas que constituam 0 objeto da aquisição. Entre as principais modificações, esta foi a maior dificuldade introduzida para o "fechamento branco" de capital.

Para testar se a Instrução CVM no 299 foi eficaz em dificultar o "fechamento branco" de capital das empresas listadas na BOVESPA, a segunda hipótese construída é a seguinte:

H2: $O$ Cumulative Abnormal Return (CAR) das ações da subamostra posterior à aprovação da CVM no 299 será superior ao CAR da subamostra anterior à aprovação da CVM ํo 299.

A terceira hipótese a ser testada pretende anal isar como o mercado reagiu aos anúncios de recompras de ações por empresas que posteriormente vieram a cancelar 0 seu registro na BOVESPA. O propósito é identificar se o mercado conseguiu separar as empresas que estavam utilizando a recompra de ações para transferência de caixa para os acionistas daquelas que utilizaram tal mecanismo para retirar liquidez do mercado acionário e, posteriormente, fechar seu capital acionário de forma mais barata, pois a quantidade e 0 preço das ações restantes seriam menores:

H3: O CAR das ações da subamostra das empresas que realizaram recompras de ações e atual mente têm suas ações transacionadas na BOVESPA é superior ao CAR das ações das empresas cujas ações, atualmente, não são mais transacionadas na BOVESPA, ou seja, tiveram seu registro cancelado na Bolsa de Valores.

\section{METODOLOGIA}

A metodologia adotada foi o estudo de evento. Utilizada por Dann (1981), Vermael en (1981) e Comment e Jarrell (1991), é uma metodologia bastante difundida na literatura para se medir os efeitos dos anúncios de recompra de ações quando há interesse em estudar os efeitos em curto prazo desses anúncios no preço das ações. Devido à racionalidade e eficiência do mercado acionário, os efeitos de um evento - no caso o anúncio de uma oferta de recompra de ações - são imediatamente traduzidos nos preços das ações da companhia realizadora da oferta. Dessa forma, medese 0 impacto de um determinado evento em uma companhia pela variação anormal da cotação de suas ações.

\section{Definição do evento}

Foi considerada como sendo a data inicial do evento denominada dia zero - a data da aprovação na RCA de cada uma das empresas, na qual se aprovou a aquisição de ações de sua própria emissão. Com o objetivo de estudar os possíveis efeitos que o anúncio de recompra pode provocar na cotação das ações dessas companhias foi necessária a definição de um período de tempo em torno da data do evento que procura abranger todos os dias de negociação das ações da empresa, cujos preços possam estar sendo afetados pelo evento em estudo. Esse período de tempo foi denominado janela do evento.

A janela do evento foi definida entre -10 e +65 devido ao fato de a aquisição de ações de sua própria emissão necessitar da aprovação do RCA e estenderse, na quase totalidade dos casos, pelo prazo máximo 
de três meses estabelecido em lei, sendo computados apenas os dias em que houve negociação na BOVESPA (ver Figura 2). Isso faz com que esses 65 dias correspondam aproximadamente aos três meses de prazo para uma empresa recomprar suas ações.

Foram contados os dez dias anteriores à data do evento com a finalidade de captar al guma movimentação de preços referente ao fato de o mercado já precificar a possibilidade de aprovação da aquisição de ações de emissão da própria empresa, cuja aprovação seria votada durante a RCA. Há ainda a possibilidade de ter havido algum vazamento de informação sobre o resultado da aprovação.

0 período de estimação utilizado foi definido entre as datas -514 e -11, um período considerado longo: dois anos, que correspondem a 504 dias de negociação na BOVESPA. A finalidade foi de desconsiderar outros fatores que pudessem influenciar o preço da ação durante curtos espaços de tempo. Outra razão para a escolha desse período longo de estimação foi o fato de uma mesma empresa poder prorrogar ou reali- zar um programa de aquisição de suas próprias ações subseqüentemente ao encerramento do programa anterior. Por essa razão, se o período de estimação de parâmetros fosse muito curto, ficaria extremamente influenciado por programas anteriores, fato evidentemente indesejado para a pesquisa.

\section{Amostra}

A amostra inicial incluiu todos os anúncios de aquisição de ações de sua própria emissão feitos por empresas listadas na BOVESPA, entre 1ㅇ de janeiro de 1994 e 30 de junho de 2002. Os dados foram coletados em via eletrônica fornecida pela BOVESPA e por meio da consulta pessoal dos autores aos Boletins Diários de Informação (BDI). Segundo esses dados, foram realizados, ao longo desse período, 647 anúncios de recompra de ações por 120 empresas distintas. Desses 647 anúncios, $523(80,83 \%$ do total) foram anúncios iniciais, sendo os restantes anúncios de prorrogação do prazo. 0 gráfico 1 mostra a evolução do número de anúncios de recompra de ações no mercado brasileiro.

Figura 2 - Definição da "janela do evento".

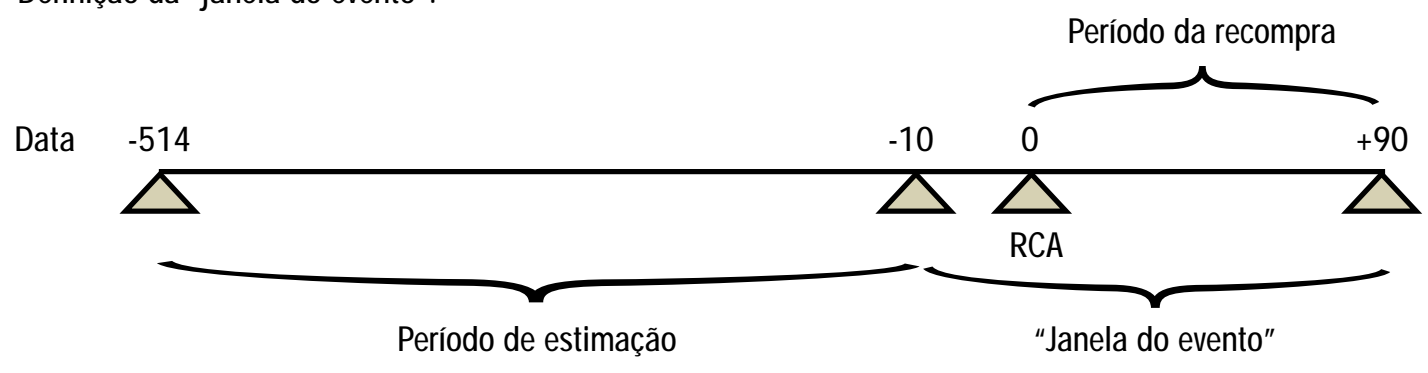

Gráfico 1 - Evolução do número de anúncios de recompra de ações na Bovespa.

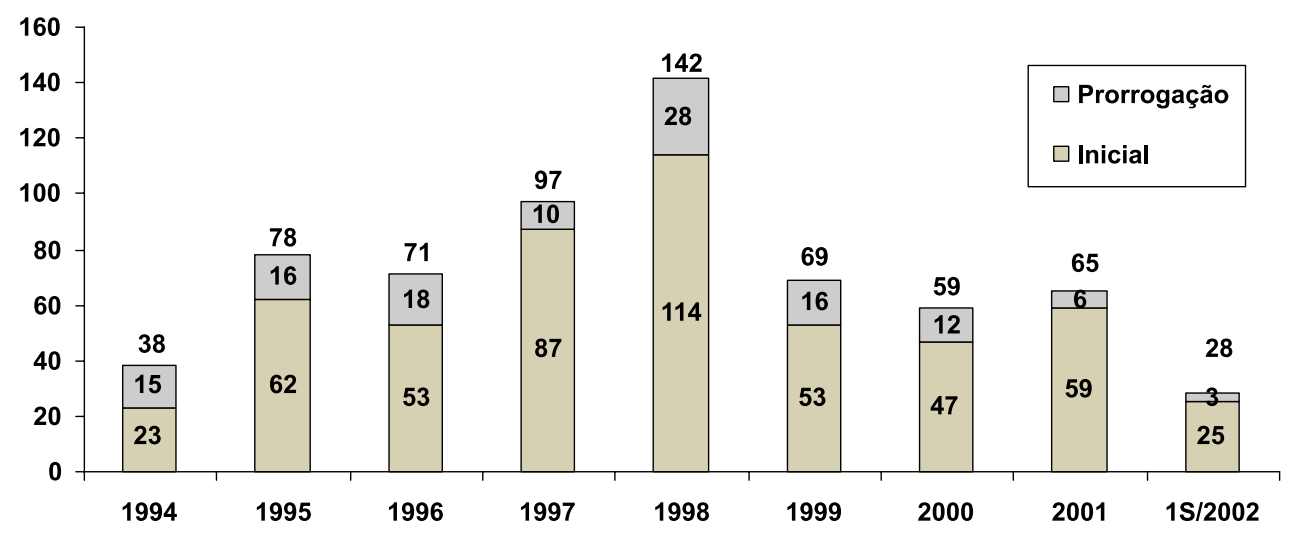

Fonte: BOVESPA 
Ao realizar um anúncio de aquisição de ações de sua própria emissão, as empresas podem anunciar a aquisição de mais de uma espécie e/ou classe de ações. $\mathrm{N}$ a maioria dos casos, durante o período analisado, as empresas o fizeram. Para a amostra anal isada, em 279 casos ( $43,12 \%$ do total) foi anunciada a recompra de apenas uma classe de ações; em 295 casos (45,60\%) a recompra de duas classes; em 56 casos $(8,66 \%)$ a recompra de três classes de ações; e em 17 casos (2,63\%) a recompra de sete classes distintas de ações da mesma empresa. Para a pesquisa, foi considerado o anúncio de recompra de cada classe de ação como sendo um evento distinto e independente. Dessa forma, os 647 anúncios feitos por empresas durante o período analisado se transformaram em 1.156 eventos distintos.

Do total de 1.156 eventos, 433 (37,5\% do total) tiveram que ser descartados por não ser possível encontrar dados do preço de suas ações no banco de dados Economática, durante o período da janela do evento e/ou do período de estimação. Esse banco de dados foi o utilizado para se obterem as cotações médias das ações presentes neste estudo. Dos 723 eventos restantes ( $62,5 \%$ do total), 201 foram descartados por não apresentarem valores de $\beta$ significativamente positivos e diferentes de zero para um nível de significância de $10 \%$ para serem utilizados nos cálculos, que serão descritos na próxima subseção, dos retornos anormais da ação durante a janela do evento.

\section{Testes realizados}

Para calcular os retornos esperados das ações, optouse por um modelo estatístico, o modelo de mercado de fator único. Fazendo uma regressão linear entre os retornos diários de uma determinada ação e a variação diária do índice IBOVESPA, foram obtidos os coeficientes $\alpha$ e $\beta$, de acordo com a equação (1):

$$
E\left(R_{i t}\right)=\alpha_{i}+\beta_{i} R_{M t}
$$

$E\left(R_{i t}\right)$ : retorno esperado da ação i na data $t$ $\mathrm{R}_{\mathrm{Mt}}$ : retorno do índice IBOVESPA na data $\mathrm{t}$

Foram consideradas as cotações médias das ações no cál culo dos retornos diários, por acreditar que reflitam melhor o verdadeiro desempenho do ativo, além do fato de serem as cotações médias as utilizadas por todos os fundos de investimento em ações do mercado brasileiro como parâmetros para a apuração de seus desempenhos diários. Todas as cotações das ações analisadas, assim como as variações diárias do índice IBOVESPA - utilizado como índice de mercado -, foram coletadas no banco el etrônico de dados E conomática e estavam ajustadas para desdobramentos, bonificações e distribuição de dividendos. Tanto as datas quanto as demais características dos anúncios de aqui sição de ações próprias foram coletadas junto à BDI. As características consideradas foram a quantidade autorizada de ações a serem recompradas, a quantidade total de ações em circulação, o prazo de duração, os motivos para a recompra, o destino das ações a serem recompradas e as corretoras envolvidas no processo.

A fim de assegurar a ausência de autocorrelação dos resíduos, realizaram-se os testes propostos por Newbold (1995) para cada evento, efetuando-se as devidas correções quando necessárias.

Após a utilização do modelo de mercado de fator único para encontrar o retorno esperado, calculamos o retorno anormal ( $A$ bnormal Return - AR) para cada ação:

$$
A R_{i t}=R_{i t}-E\left(R_{i t}\right)
$$

Calcularam-se os retornos anormais acumulados (CAR) para cada ação até a data $T$ :

$$
C A R_{i T}=\sum_{t=1}^{T} A R_{i t}
$$

Em seguida, foi calculado o desvio padrão amostral para cada subamostra, a partir da matriz de resíduos das regressões. Para isso, foram calculadas as médias cross-section dos resíduos para cada dia (de -414 a-11) e o desvio padrão amostral da série temporal de resíduos médios das regressões, multiplicado pela raiz quadrada do número de dias incluídos no cálculo do CAR, o que resulta no desvio padrão do CAR de cada subamostra, de acordo com a fórmula a seguir:

$$
s\left(C A R_{T}\right)=s_{R} \sqrt{(T+11)}
$$

$S\left(\mathrm{CAR}_{\mathrm{T}}\right)$ : desvio padrão do $\mathrm{CAR}_{\mathrm{T}}$ $S_{R}$ : desvio padrão da série temporal de resíduos médios das regressões

Observa-se que, na fórmula anterior, foi utilizado 0 termo $(T+11)$. Isso se deve ao fato de se calcularem os retornos anormais acumulados a partir da data -10 , incluindo a data zero. Por exemplo, no cálculo do CAR65, foram incluídos os dias de -10 a +65 , o que equivale a 76 dias.

De posse dos retornos anormais acumulados para cada subamostra e de seus respectivos desvios padrão, 
verificou-se se as diferenças entre os CARs das subamostras são significativamente diferentes de zero. Real izou-se esse procedimento para as datas -10 a +65 . Para testar se a diferença entre os retornos anormais acumulados das subamostras era significativamente positiva, utilizou-se a seguinte fórmula:

$$
t=\frac{C A R_{A}-C A R_{B}}{\sqrt{\frac{\left(\sigma_{A}\right)^{2}}{n_{A}}+\frac{\left(\sigma_{B}\right)^{2}}{n_{B}}}}
$$

\section{RESULTADOS E DISCUSSÃO}

A Tabela 1 apresenta os resultados referentes à média dos retornos anormais $(A R)$ e à média dos retornos anormais acumulados (CAR) para toda a amostra final estudada.

0 resultado obtido com a amostra total revela um forte efeito de sinal ização nos dois primeiros dias após 0 anúncio da recompra de ação, somando um total de 0,896\% de retorno anormal. Desse total, o primeiro dia apresentou um retorno anormal de $0,541 \%$, enquanto o segundo apresentou um retorno anormal de $0,355 \%$. A mbos são significativamente maiores do que zero, com estatísticas t-student de 3,473 e 2,280 respectivamente.

A pós esses dois dias iniciais posteriores ao anúncio do programa de recompra de ações, o preço se manteve num patamar bastante estável até o décimo dia pós-anúncio, para depois começar a cair de maneira razoavel mente constante até o final do prazo da recompra, totalizando uma queda de $4,5 \%$ entre $010^{\circ}$ e 0 65 dia. Tal comportamento de que- da dos preços após o $10^{\circ}$ dia também foi encontrado por Lasfer (2002) para a Europa continental, embora em menor escala. Esse resultado poderia ser explicado por uma penalização do mercado às empresas que utilizam programas de recompra de ações, por estes terem desvantagens fiscais em relação ao pagamento de dividendos, o que faria os investidores preferirem a distribuição de caixa via pagamento de dividendos. Isso também pode ser visto, no caso brasileiro, como sendo uma penalização do mercado contra empresas que utilizavam a recompra de ações para tirar liquidez da ação - "fechamento branco" de capital - e prejudicar os acionistas. U ma ilustração dos CARs de toda a amostra analisada pode ser visto no Gráfico 2.

As segunda e terceira hipóteses visam justamente testar esse comportamento do mercado. Em ambos os testes o resultado obtido corroborou de forma muito significativa que, antes da aprovação da I nstrução CVM no 299, o mercado penalizava as empresas que recompravam suas ações e, posteriormente à aprovação da Instrução, passou a avaliar positivamente as empresas que anunciaram programas de recompra de ações. A Tabela 2 apresenta os valores dos CARs e dos ARs para as subamostras antes e depois da Instrução CVM no 299, com a significância estatística da diferença entre elas.

É importante observar que antes da Instrução CVM no 299 não é possível visualizar um aumento anormal significativo do preço das ações analisadas, mesmo nos dois primeiros dias após o anúncio da recompra de ações. Além disso, no retorno total acumulado durante o período de recompra as ações perderam, em média, quase $10 \%$ do seu valor após o anúncio, sendo essa queda estatisticamente significativa.

Tabela 1 - Resultados dos CARs e ARs para toda a amostra final analisada.

\begin{tabular}{|r|ll|ll|}
\hline & CAR & t-stat & AR & t-stat \\
\hline-10 & $-0,142 \%$ & $(0,91)$ & $-0,142 \%$ & $(0,91)$ \\
\hline-5 & $-1,196 \%$ & $(3,14)^{* * *}$ & $-0,056 \%$ & $(0,36)$ \\
\hline-2 & $-2,154 \%$ & $(4,61)^{* * *}$ & $-0,446 \%$ & $(2,86)^{* * *}$ \\
\hline-1 & $-2,663 \%$ & $(5,41)^{* * *}$ & $-0,509 \%$ & $(3,27)^{* * *}$ \\
\hline 0 & $-2,971 \%$ & $(5,75)^{* * *}$ & $-0,307 \%$ & $(1,97)^{* *}$ \\
\hline 1 & $-2,430 \%$ & $(4,51)^{* * *}$ & $0,541 \%$ & $3,47 * * *$ \\
\hline 2 & $-2,075 \%$ & $(3,70)^{* * *}$ & $0,355 \%$ & $2,28 * * *$ \\
\hline 5 & $-1,947 \%$ & $(3,13)^{* * *}$ & $0,057 \%$ & 0,37 \\
\hline
\end{tabular}

\begin{tabular}{|l|ll|rl|}
\hline & CAR & t-stat & AR & t-stat \\
\hline 10 & $-1,813 \%$ & $(2,54)^{* *}$ & $0,147 \%$ & 0,94 \\
\hline 15 & $-2,720 \%$ & $(3,43)^{* * *}$ & $-0,238 \%$ & $(1,53)$ \\
\hline 20 & $-3,020 \%$ & $(3,48)^{* * *}$ & $-0,150 \%$ & $(0,97)$ \\
\hline 25 & $-3,650 \%$ & $(3,91)^{* * *}$ & $-0,050 \%$ & $(0,32)$ \\
\hline 35 & $-4,512 \%$ & $(4,27)^{* * *}$ & $0,006 \%$ & 0,04 \\
\hline 45 & $-4,934 \%$ & $(4,24)^{* * *}$ & $-0,389 \%$ & $(2,50)^{* *}$ \\
\hline 55 & $-6,016 \%$ & $(4,76)^{* * *}$ & $-0,224 \%$ & $(1,44)$ \\
\hline 65 & $-6,450 \%$ & $(4,75)^{* * *}$ & $-0,194 \%$ & $(1,25)$ \\
\hline
\end{tabular}

* significativo a $10 \% ; * *$ significativo a $5 \%$; *** significativo a $1 \%$ 
Entretanto, a situação se inverteu após a aprovação da Instrução CVM no 299. É possível visualizar um aumento anormal altamente positivo nos dois primeiro dias posteriores ao anúncio da recompra - com estatística t-student de 5,693 e 2,109 respectivamente - , ao passo que no acumulado até o final do período de recompra se pode observar um retorno anormal acumulado positivo de mais de $4 \%$ - com estatística tstudent de 2,03. A diferença entre as duas subamostras é também muito significativa estatisticamente - ao nível de $1 \%$ para todos os dias após o anúncio da recompra. Isso demonstra que a Instrução CVM no 299 separa a amostra inicial em duas subamostras bastante diferentes entre si, o que pode ser visualmente observado no Gráfico 3.

0 perfil dos retornos apresentados após a aprovação da instrução CVM no 299 é semelhante ao encontrado por Comment e Jarrell (1991), com uma forte al ta nos dois primeiros dias após o anúncio e uma elevação mais gradual dos preços pelo resto do período

Gráfico 2 - Gráfico dos CARs da Hipótese 1 - Impacto do anúncio de recompra.

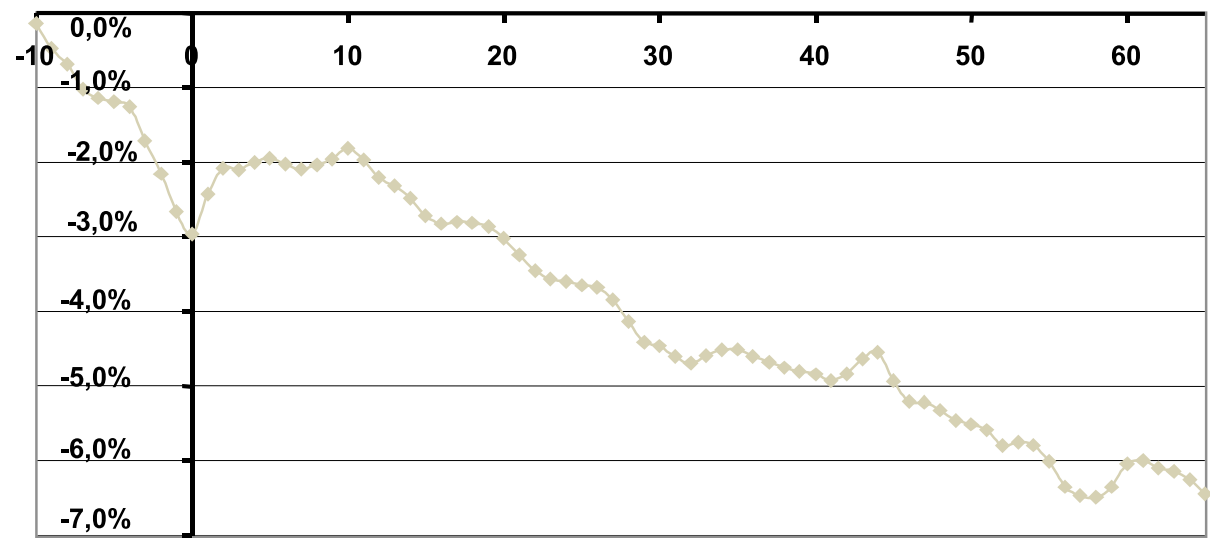

Tabela 2 - Resultados da Hipótese 2 - Influência da Instrução CVM № 299.

\begin{tabular}{|c|c|c|c|c|c|c|c|c|c|}
\hline & \multicolumn{4}{|c|}{$\begin{array}{l}\text { ANTES DA } \\
\text { CVM } 299\end{array}$} & \multicolumn{4}{|c|}{$\begin{array}{l}\text { DEPOIS DA } \\
\text { CVM } 299\end{array}$} & \multirow{2}{*}{$\begin{array}{c}\text { DEPOIS DA CVM } \\
\text { - ANTES DA CVM } \\
\text { t-stat }\end{array}$} \\
\hline & CAR & t-stat & $\mathrm{AR}$ & t-stat & CAR & t-stat & $\mathrm{AR}$ & t-stat & \\
\hline-10 & $-0,16 \%$ & $(0,79)$ & $-0,16 \%$ & $(0,79)$ & $-0,11 \%$ & $(0,46)$ & $-0,11 \%$ & $(0,46)$ & 0,11 \\
\hline-5 & $-1,92 \%$ & $(3,91)^{* * *}$ & $-0,19 \%$ & $(0,95)$ & $-0,01 \%$ & $(0,02)$ & $0,16 \%$ & 0,68 & $1,82^{*}$ \\
\hline-1 & $-4,02 \%$ & $(6,34) * * *$ & $-0,69 \%$ & $(3,45) * * *$ & $-0,44 \%$ & $(0,58)$ & $-0,21 \%$ & $(0,87)$ & $2,64 * * *$ \\
\hline 0 & $-4,38 \%$ & $(6,59) * * *$ & $-0,36 \%$ & $(1,80)^{*}$ & $-0,66 \%$ & $(0,82)$ & $-0,22 \%$ & $(0,91)$ & $2,61 * * *$ \\
\hline 1 & $-4,35 \%$ & $(6,26)^{* * *}$ & $0,03 \%$ & 0,14 & $0,72 \%$ & 0,86 & $1,38 \%$ & $5,69 * * *$ & $3,41 * * *$ \\
\hline 2 & $-4,09 \%$ & $(5,66)^{* * *}$ & $0,26 \%$ & 1,29 & $1,23 \%$ & 1,41 & $0,51 \%$ & $2,11 * *$ & $3,44 * * *$ \\
\hline 5 & $-4,15 \%$ & $(5,17)^{* * *}$ & $0,03 \%$ & 0,13 & $1,65 \%$ & $1,70 *$ & $0,11 \%$ & 0,44 & $3,38 * * *$ \\
\hline 10 & $-4,31 \%$ & $(4,68)^{* * *}$ & $0,06 \%$ & 0,32 & $2,27 \%$ & $2,04 * *$ & $0,28 \%$ & 1,16 & $3,34 * * *$ \\
\hline 15 & $-5,70 \%$ & $(5,57) * * *$ & $-0,39 \%$ & $(1,96)^{*}$ & $2,16 \%$ & $1,75^{*}$ & $0,02 \%$ & 0,07 & $3,59 * * *$ \\
\hline 25 & $-7,48 \%$ & $(6,21)^{* * *}$ & $-0,19 \%$ & $(0,95)$ & $2,62 \%$ & $1,80 *$ & $0,18 \%$ & 0,75 & $3,92 * * *$ \\
\hline 45 & $-9,79 \%$ & $(6,52) * * *$ & $-0,27 \%$ & $(1,37)$ & $3,01 \%$ & $1,66 *$ & $-0,58 \%$ & $(2,38)^{* *}$ & $3,99 * * *$ \\
\hline 65 & $-13,01 \%$ & $(7,44)^{* * *}$ & $-0,24 \%$ & $(1,22)$ & $4,29 \%$ & $2,03 * *$ & $-0,11 \%$ & $(0,46)$ & $4,63 * * *$ \\
\hline
\end{tabular}

* significativo a $10 \%$; ** significativo a $5 \%$; *** significativo a $1 \%$ 
da recompra. No estudo de Comment e Jarrell (1991) existe uma forte queda nos dias anteriores ao anúncio da recompra, fato de difícil identificação nos resultados encontrados da presente pesquisa. Isso é devido ao fato de a janela do evento antes do anúncio ser bastante reduzida, exatamente para que os efeitos de uma baixa performance da companhia no período anterior ao anúncio não influenciassem os resultados obtidos.

0 resultado da terceira hipótese também ocorreu de acordo com o esperado (ver Tabela 3). Mostrou que antes da CVM no 299 o mercado penalizou, após os anúncios de recompra de ações, as empresas que vieram a fechar seu capital posteriormente - até 30 de junho de 2002. Isso pode indicar que tais empresas não estavam interessadas em distribuir caixa para seus acionistas, mas em retirar liquidez do mercado. Talvez fosse um "fechamento branco" de capital das empresas, diminuindo seu preço e facilitando um futuro fechamento de capital. É importante notar que não há um único anúncio de aquisição de ações de sua própria emissão por companhias que posteriormente viessem a cancelar seu registro junto à BOVESPA, após a

Gráfico 3 - CARs da Hipótese 2 - Impacto da Instrução CVM № 299.

(A) antes da CVM 299

(B) depois da CVM 299

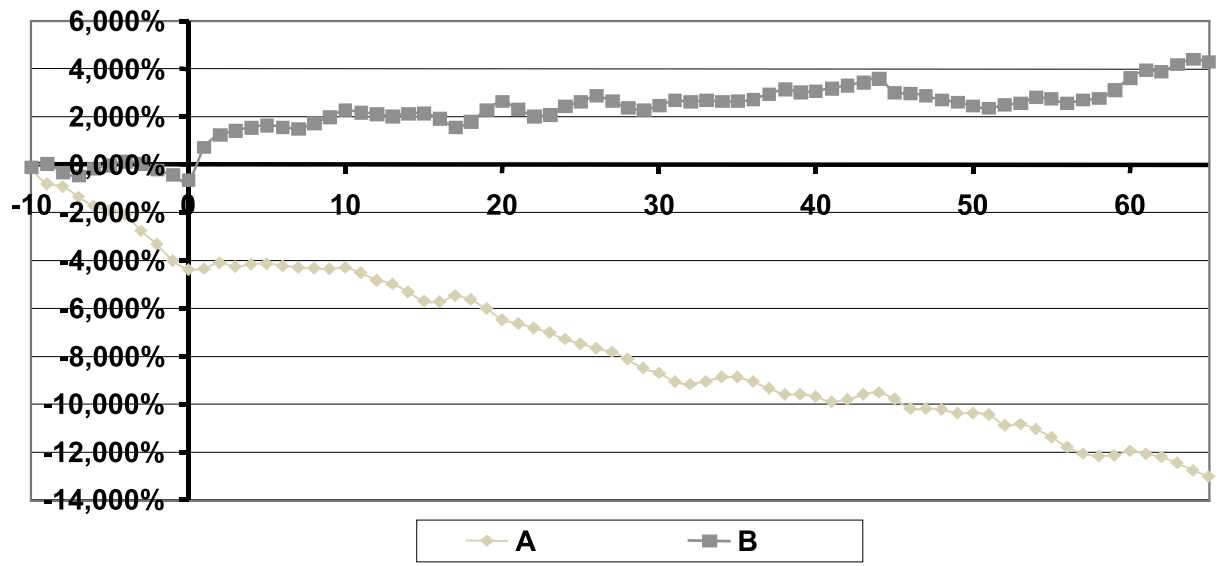

Tabela 3 - Resultados da Hipótese 3 - Cancelamento de registro na BOVESPA.

\begin{tabular}{|c|c|c|c|c|c|c|c|c|c|c|}
\hline \multicolumn{11}{|c|}{ CAR } \\
\hline & \multicolumn{2}{|c|}{ A Reg Canc } & \multicolumn{2}{|c|}{ D Reg Canc } & \multicolumn{2}{|c|}{ A Reg Ab } & \multicolumn{2}{|c|}{$D$ Reg Ab } & \multirow{2}{*}{$\begin{array}{c}\text { A Reg Ab - } \\
\text { A Reg Canc } \\
\text { t-stat }\end{array}$} & \multirow{2}{*}{$\begin{array}{c}\text { D Reg Ab - } \\
\text { A Reg Ab } \\
\text { t-stat }\end{array}$} \\
\hline & $n=58$ & t-stat & $n=0$ & t-stat & $n=266$ & t-stat & $n=198$ & t-stat & & \\
\hline-10 & $0,05 \%$ & 0,09 & & & $-0,20 \%$ & $(1,03)$ & $-0,11 \%$ & $(0,46)$ & $(0,25)$ & 0,21 \\
\hline-5 & $-2,29 \%$ & $(1,79)^{*}$ & & & $-1,84 \%$ & $(3,79) * * *$ & $-0,01 \%$ & $(0,02)$ & 0,19 & $1,68 *$ \\
\hline 0 & $-5,91 \%$ & $(3,42)^{* * *}$ & & & $-4,05 \%$ & $(6,15)^{* * *}$ & $-0,66 \%$ & $(0,82)$ & 0,57 & $2,30 * *$ \\
\hline 5 & $-5,02 \%$ & $(2,41)^{* *}$ & & & $-3,95 \%$ & $(4,98)^{* * *}$ & $1,65 \%$ & $1,70 *$ & 0,27 & $3,16 * * *$ \\
\hline 10 & $-5,58 \%$ & $(2,34)^{* *}$ & & & $-4,03 \%$ & $(4,43)^{* * *}$ & $2,27 \%$ & $2,04 * *$ & 0,34 & $3,10 * * *$ \\
\hline 15 & $-6,33 \%$ & $(2,38) * *$ & & & $-5,56 \%$ & $(5,50) * * *$ & $2,16 \%$ & $1,75 *$ & 0,15 & $3,41 * * *$ \\
\hline 25 & $-11,92 \%$ & $(3,82) * * *$ & & & $-6,51 \%$ & $(5,47)^{* * *}$ & $2,62 \%$ & $1,80 *$ & 0,91 & $3,43 * * *$ \\
\hline 45 & $-18,28 \%$ & $(4,69) * * *$ & & & $-7,94 \%$ & $(5,35)^{* * *}$ & $3,01 \%$ & $1,66 *$ & 1,40 & $3,30 * * *$ \\
\hline 65 & $-23,79 \%$ & $(5,24)^{* * *}$ & & & $-10,67 \%$ & $(6,16)^{* * *}$ & $4,29 \%$ & $2,03 * *$ & 1,53 & $3,87 * * *$ \\
\hline
\end{tabular}

* significativo a $10 \%$; ** significativo a $5 \%$; *** significativo a $1 \%$ 
instrução CVM no 299. Dessa forma, os resultados obtidos na segunda e na terceira hipóteses formuladas indicam que a Instrução CVM no 299 agiu a favor de seus objetivos de dificultar o "fechamento branco" de capital e proteger os acionistas minoritários. Saito (2001) também encontrou resultados positivos dessa instrução da CVM na proteção dos direitos dos acionistas minoritários.

É importante ressaltar que, devido à não normalidade das amostras estudadas, foram realizados testes não paramétricos para a comparação de medianas testes de Wilcoxon - para todas as hipóteses testadas, com o intuito de verificar a consistência dos testes tstudent realizados. Todos os resultados encontrados foram compatíveis com os resultados dos testes paramétricos apresentados, reforçando ainda mais a consistência da análise (ver Tabela 4).

\section{CONCLUSÃO}

A análise empírica evidencia a influência positiva da introdução da Instrução CVM no 299 no comportamento do preço das ações das companhias brasileiras após o anúncio de programas de recompra de ações. Antes dessa Instrução, havia uma queda acumulada nos preços das ações dessas companhias de em média - $10 \%$ durante os três meses do período autorizado para a recompra das ações. $N$ ão há resultados semelhantes em nenhum dos trabalhos analisados de outros países.

Entretanto, após a promulgação da Instrução CVM no 299, as ações passam a obter retornos anormais acumulados positivos de cerca de $2 \%$ nos primeiros 2 dias após 0 anúncio e mais $2 \%$ até 0 final do prazo legal estipulado para o programa de recompra. Considerando-se a mesma janela de evento, esses resultados são semel hantes aos encontrados no mercado norte-americano por Vermaelen (1981) e Comment e Jarrel (1991), nos quais também há um aumento entre 2 e $3 \%$ no preço das ações nos dias subseqüentes ao do anúncio. Os preços se mantêm razoavel mente estáveis pelos 60 dias seguintes, ou com ou aumento gradual de cerca de $2 \%$ nos 50 dias seguintes. Os resultados também são semel hantes aos encontrados no mercado canadense por Li e McNally (1999), embora, nesse caso, o CAR nos primeiros dias após o anúncio fosse maior, de cerca de $6 \%$.

Dessa forma, há evidências para não se rejeitar a hipótese 2, qual seja, a de que a Instrução CVM no 299 proporcionou benefícios aos acionistas minoritários, proporcionando-Ihes retornos anormais positivos, com uma diferença média maior do que $12 \%$ para o período compreendido entre 0 anúncio e o término do prazo legal.

Também há evidências para não se rejeitar a hipótese 3, qual seja, de que houve uma inibição do "fechamento branco" de capital por companhias negociadas na BOVESPA. Isso por ser possível observar que, após a Instrução CVM no 299, nenhuma companhia que veio a cancel ar seu registro junto à BOVESPA utilizou a mecânica de recompra de ações, fato que ocorria anteriormente. É importante notar que mesmo antes da Instrução CVM no 299 o mercado parecia avaliar pior as empresas que vieram a fechar 0 seu capital posteriormente, embora tal resultado não seja significativo para o nível de $10 \%$ do teste tstudent, mas o seja para o nível de $5 \%$ do teste não paramétrico de Wilcoxon.

Por fim, os resultados encontrad os também são compatíveis com a teoria da sinalização, no que se refere aos retornos anormais significativamente positivos logo nos primeiros dois dias após o anúncio da recompra de ações.

Tabela 4 - Resultados do teste paramétrico t-student com o teste de Wilcoxon para comparação de medianas.

\begin{tabular}{|c|c|c|c|c|}
\hline & HIPÓTESE TESTADA & TESTE t-student & TESTE WIL & LCOXON \\
\hline $\mathrm{H} 1$ & Amostra total & $(4,75) * * *$ & $(4,93)$ & $* * *$ \\
\hline \multirow[t]{3}{*}{$\mathrm{H} 2$} & Antes CVM no 299 & $(7,44) * * *$ & $(6,90)$ & $* * *$ \\
\hline & Depois CVM no 299 & $2,03 * *$ & 1,54 & \\
\hline & Depois CVM no 299 - Antes CVM no 299 & 4,63 & 6,28 & $* * *$ \\
\hline \multirow[t]{3}{*}{ H3 } & REG AB - REG CANC & 2,32 & 3,79 & $* * *$ \\
\hline & A Reg Ab - A Reg Canc & 1,53 & 2,35 & $* *$ \\
\hline & D Reg Ag - A Reg Ag & 3,87 & 5,55 & $* * *$ \\
\hline
\end{tabular}

* significativo a $10 \%$; ** significativo a $5 \%$; *** significativo a $1 \%$ 


\title{
MARCIO FERNANDES GABRIELLI •RICHARD SAITO
}

\section{REFERÊNCIAS BIBLIOGRÁFICAS}

BAGWELL, L. S. Dutch Auction Repurchase: An Analysis of Shareholder Heterogeneity. The Journal of Finance, v. 47, n. 1, p. 71-105, 1992.

BARCLAY, M.; SMITH, C. Corporate Payout Policy: Cash Dividends versus Open Market Repurchases. Journal of Financial Economics, v. 22, n. 1, 1988.

BROCKMAN , P.; CHUNG, D. Managerial Timing and Corporate Liability: Evidence from Actual Share Repurchases. Journal of Financial Economics, $v$. 61, n. 3, 2001.

COMMENT, R.; JARRELL, G. A. The Relative Signaling Power of DutchAuction and Fixed-Price Self-Tender Offers and Open-Market Share Repurchases. Journal of Finance, v. 46, n. 4, p. 1243-1271, 1991.

COOK, D. et al. Corporate Repurchase Programs: Execution Strategy and the Competing-Market-Maker Effect. Working Paper, University of Colorado (USA), 1996.

DANN, L. Y. Common Stock Repurchases - An Analysis of Returns to Bondholders and Stockholders. Journal of Financial Economics, v. 9, n. 2, p. 113-138, 1981.

GRIN BLATT, M.; TITMAN, S. Financial M arkets and Corporate Strategy. 2. ed. New York: McGraw-Hill, 2002.

GRULLON, G.; MICHAELY, R. Dividends, Share Repurchases, and the Substitution Hypothesis. Journal of Finance, v. 57, n. 4, 2002.

GUAY, W.; HARFORD, J. The Cash Flow Permanence and Information Content of Dividend Increases versus Repurchases. Journal of Financial Economics, v. 57, n. 3, 2000

IKENBERRY, D. et al. Market Underreaction to Open Market Share Repurchases. Journal of Financial Economics, v. 39, n. 2/3, p. 181-208, 1995.

IKENBERRY, D. et al. Stock Repurchases in Canada: Performance and Strategic Trading. Journal of Finance, v. 55, n. 5, p. 2373-2397, 2000.

JAGANNATHAN, M. et al. Financial Flexibility and the Choice Between Dividends and Stock Repurchases. Journal of Financial Economics, v. 57, n. 3, p. 355-384, 2000 .

JENSEN, M. C.; MECKLING, W. Theory of the Firm: Managerial Behavior, Agency Costs and O wnership Structure. Journal of Financial Economics, v. 3, n. 4, 1976.
KIM, J.; SCHREM PER, R. Cross-Country Examination of Open Market Repurchase Regulations: Do They Create a Conflict of Interest in the U.S.? Working Paper, University of Oregon (USA), 2002.

LAKONISHOK, J.; VERMAELEN, T. Anomalous Price Behavior Around Repurchase Tender O ffers. Journal of Finance, v. 45, n. 2, p. 455-477, 1990.

LA PORTA, R. et al. Agency Problems and Dividend Policies Around the World. Journal of Finance, v. 55, n. 1, p. 1-33, 2000.

LASFER, M. A. The Market Valuation of Share Repurchases in Europe. Working Paper, City University Business School (UK), 2002.

LI, K.; MCNALLY, W. Information Signaling or Agency Conflicts: What Explain Canadian Open Market Share Repurchases? Working Paper of the University of British Columbia and the University of Victoria, February, 1999.

LIE, E.; LIE, H. J. The Role of Personal Taxes in Corporate Decisions: An Empirical Analysis of Share Repurchases and Dividends. Journal of Financial \& Quantitative Analysis, v. 34, n. 4, p. 533-552, 1999

MILLER, J.; MCCONNELL, J. Open-Market Share Repurchase Programs and Bid-Ask Spreads on the NYSE: Implications for Corporate Payout Policy. Journal of Financial \& Quantitative Analysis, v. 30, n. 3, 1995.

PROCIANOY, J. L.; MOREIRA, L. F. O pen Market Stock Repurchases at BOVESPA, BALAS, 2000

SAITO, Richard. Determinants of the Differential Pricing between Voting and Non-Voting Shares in Brazil. Brazilian Review of Econometrics, v. 23, n. 1, 2003.

SAITO, R. Share Repurchase Mechanisms and Expropriation of Minority Shareholders: Evidence from Brazil. In: ENCONTRO ANUAL DA ASSOCIAÇÃO NACIONAL DE PÓS-GRADUAÇÃO EM ADMINISTRAÇÃO, 2001. Anais. Campinas: AN PAD, 2001.

STEPHENS, C. P.; WEISBACH, M. S. Actual Share Reacquisition in O pen Market Repurchase Programs. The Journal of Finance, v. 53, n. 1 , p. 313-334, 1998.

VERMAELEN, T. Common Stock Repurchases and Market Signaling Journal of Financial Economics, v. 9, n. 2, p. 139-183, 1981.

VERMAELEN, T. Repurchase Tender Offers, Signaling, and Managerial Incentives. Journal of Financial \& Quantitative Analysis, v. 19, n. 2, p. 163-181, 1984.

WEISBEN NER, Scott J. Corporate Share Repurchases in the 1990s: What Role Do Stock O ptions Play? Working Paper of the N ational Reserve Board (USA), April 2000.

Artigo recebido em 11.11.2003. Aprovado em 05.05.2004.

\author{
Marcio Fernandes Gabrielli \\ Professor da Escola Superior de Propaganda e Marketing. M estre em Administração de Empresas pela FGV-EAESP. \\ Interesses de pesquisa na área de finanças. \\ E-mail: mfgabrielli@terra.com.br \\ Endereço: Rua São Vicente de Paulo, 367, apto 52, Higienópolis, São Paulo - SP, 01229-010.
}

\section{Richard Saito}

Professor Titular do Departamento de Contabilidade, Finanças e Controle da FGV-EAESP. Ph.D. em Engenharia econômica pela Stanford University. Interesses de pesquisa na área de finanças.

E-mail: rsaito@fgvsp.br

Endereço: Av. 9 de Julho, 2029, 11o andar, Departamento de Finanças, Bela Vista, São Paulo - SP, 01313-902. 